\title{
Medicaid's Impact on Chronic Disease Biomarkers: A Cohort Study of Community Health Center Patients
}

\author{
Brigit Hatch, $M D M P H^{1,2}$, Miguel Marino, $P h D^{7}$, Marie Killerby, VetMB $M P H^{7}$, Heather Angier, $M P H^{7}$, \\ Megan Hoopes, $M P H^{2}$, Steffani R Bailey, $P h D^{7}$, John Heintzman, $M D M P H^{7}$, Jean $P O^{\prime} M a l l e y, M P H^{7}$, \\ and Jennifer E DeVoe, MD DPhil ${ }^{1,2}$
}

'Oregon Health \& Science University, Portland, OR, USA; ${ }^{2} \mathrm{OCHIN}$, Inc., Portland, OR, USA.

BACKGROUND: Understanding the impact of health insurance is critical, particularly in the era of Affordable Care Act Medicaid expansion. The electronic health record (EHR) provides new opportunities to quantify health outcomes.

OBJECTIVE: To assess changes in biomarkers of chronic disease among community health center (CHC) patients who gained Medicaid coverage with the Oregon Medicaid expansion (2008-2011).

DESIGN: Prospective cohort. Patients were followed for 24 months, and rate of mean biomarker change was calculated. Time to a controlled follow-up measurement was compared using Cox regression models.

SETTING/PATIENTS: Using EHR data from OCHIN (a non-profit network of CHCs) linked to state Medicaid data, we identified three cohorts of patients with uncontrolled chronic conditions (diabetes, hypertension, and hyperlipidemia). Within these cohorts, we included patients who gained Medicaid coverage along with a propensity score-matched comparison group who remained uninsured (diabetes $n=608$; hypertension $n=1244$; hyperlipidemia $n=546$ ).

MAIN MEASURES: Hemoglobin Alc (HbAlc) for the diabetes cohort, systolic and diastolic blood pressure (SBP and DBP, respectively) for the hypertension cohort, and low-density lipoprotein (LDL) for the hyperlipidemia cohort.

KEY RESULTS: All cohorts improved over time. Compared to matched uninsured patients, adults in the diabetes and hypertension cohorts who gained Medicaid coverage were significantly more likely to have a follow-up controlled measurement (hazard ratio $[\mathrm{HR}]=1.26, p=$ $0.020 ; \mathrm{HR}=1.35, p<0.001$, respectively). No significant difference was observed in the hyperlipidemia cohort ( $\mathrm{HR}=1.09, p=0.392)$.

CONCLUSIONS: OCHIN patients with uncontrolled chronic conditions experienced objective health improvements over time. In two of three chronic disease cohorts, those who gained Medicaid coverage were more likely to achieve a controlled measurement than those who remained uninsured. These findings demonstrate the ef-

Electronic supplementary material The online version of this article (doi:10.1007/s11606-017-4051-9) contains supplementary material, which is available to authorized users.

Received August 1, 2016

Revised December 5, 2016

Accepted March 14, 2017

Published online April 3, 2017 fective care provided by $\mathrm{CHCs}$ and the importance of health insurance coverage within a usual source of care setting.

Clinical Trials Registration: NCT02355132 [https://clinicaltrials.gov/ct2/show/NCT02355132]

KEY WORDS: Medicaid; access to healthcare; biomarkers. J Gen Intern Med 32(8):940-7

DOI: $10.1007 / \mathrm{s} 11606-017-4051-9$

(C) Society of General Internal Medicine 2017

\section{INTRODUCTION}

In 2014, implementation of the Affordable Care Act (ACA) reshaped the landscape of health insurance in America. During the first 15 months, more than 13 million Americans gained coverage through federally sponsored state Medicaid expansion that increased eligibility to adults making up to $138 \%$ of the federal poverty level (FPL). Though some of these individuals had insurance previously, most were uninsured. ${ }^{1}$ With the increased access to health insurance, it is important to understand the health impacts of gaining coverage.

Community health centers (CHCs) provide healthcare for uninsured Americans as well as those with Medicaid coverage; before implementation of the ACA, CHCs provided 61 million medical care visits, over $35 \%$ of which were to uninsured patients. ${ }^{2}$ Despite lack of health insurance, many $\mathrm{CHC}$ patients receive care for acute and chronic conditions and preventive care. ${ }^{3,4}$ This care often comes at deeply discounted rates made possible by alternative funding sources. ${ }^{5}$ These clinics fill a critical need by providing high-quality care regardless of insurance status. ${ }^{3,6-8}$ Therefore, understanding whether Medicaid expansion has an additive impact on the excellent care received by $\mathrm{CHC}$ patients is crucial.

A large body of research emphasizes the association between access to health insurance, receipt of needed care, and improved health outcomes. ${ }^{9-13}$ Oregon independently expanded Medicaid to the FPL prior to implementation of the ACA, and randomly selected applicants from a pool of individuals who added their names to a reservation list. ${ }^{13}$ Studies from Oregon's Medicaid expansion show that individuals report improvement in perceived health and less financial hardship, but the impact of Medicaid insurance on health 
outcomes is mixed. ${ }^{14-16}$ Past studies have not fully accounted for access to a usual source of primary care and have employed surrogate measures of health outcomes (i.e., an individual's recollection of their disease control) instead of measured biomarker change.

By providing an accurate, objective report of disease biomarkers, the electronic health record (EHR) offers the opportunity for a new perspective on the health impacts of Medicaid. The EHR also allows for evaluation of an uninsured comparison group normally excluded from claims-based studies. A few studies have used the EHR to assess biomarkers of chronic disease, but use of the EHR to assess the impact of health insurance expansion on biomarker change is a novel approach. When linked to state Medicaid records, these data can provide a longitudinal perspective of the quality of healthcare and impact of Medicaid among patients with a usual source of care. Because longterm data on the effects of the ACA are only now becoming available, we must examine past Medicaid expansions to assess the potential impact of these policies.

To meet this need, we assessed changes in biomarkers of chronic disease among $\mathrm{CHC}$ patients with uncontrolled chronic conditions who gained new Medicaid coverage compared to a matched set of patients who remained continuously uninsured during a period of Medicaid expansion in Oregon (2008-2011). Here, we focus on cardiovascular disease, since it is the leading cause of death in the United States. Specifically, we include the following cardiovascular disease risk factors: high blood pressure, high low-density lipoprotein (LDL) cholesterol, and diabetes. ${ }^{17}$ Many cardiovascular conditions and associated morbidities are preventable with timely preventive care, yet rates of receipt of age-appropriate preventive services remain suboptimal, and inequities exist. ${ }^{18-21}$

\section{METHODS}

\section{Data Sources}

OCHIN Electronic Health Record (EHR). OCHIN, Inc. (not an acronym) is a nonprofit health information technology organization providing a centrally hosted, linked instance of the Epic ${ }^{\circledR}$ EHR to its members. EHR data are managed, validated, cleaned, and warehoused at OCHIN. ${ }^{22}$ We used OCHIN EHR data to extract demographic and encounter information, including biomarker measurements taken during clinic visits.

Medicaid Enrollment Data. We obtained Medicaid enrollment data from the state of Oregon and linked it to EHR data using unique Medicaid patient identifiers. We utilized this data set to define the cohort of patients with coverage during the study period and to identify Medicaid coverage dates.

\section{Study Population}

Patients were required to have an initial uncontrolled biomarker result recorded in the EHR within 6 months before or after the date they gained Medicaid coverage. All participants were adult $\mathrm{CHC}$ patients who gained Oregon Medicaid coverage between 2008 and 2011 after being uninsured for a period of $\geq 6$ months. Patients were included if, for the entire study period (defined below), they were aged 19-64, not pregnant, not deceased, and had no evidence of private or Medicare insurance. We followed each patient in the EHR for 24 months from his or her initial elevated biomarker reading. To examine biomarker changes over time, we included only patients with a follow-up measurement during the study period. Because some patients had no follow-up measurement during this period (11.9\% for diabetes, $3.6 \%$ for hypertension, and $34.4 \%$ for hyperlipidemia cohorts), we performed a sensitivity analysis of the "full population," including those without a follow-up measurement (see online Appendix).

We used propensity score methodology to match insured patients to a comparison group who met the same inclusion criteria but were continuously uninsured throughout the 24month study period. Propensity score models included baseline variables for demographics (e.g., age, race/ethnicity, federal poverty level, baseline biomarker result, disease-specific medication prescription in the pre-period), insurance history, CHC utilization (e.g., number of encounters in pre-period, number of biomarker measurements in the pre-period), comorbidities (e.g., number of chronic conditions), and health center characteristics based on the Aday and Andersen behavioral model of health services utilization ${ }^{23}$ and prior studies. ${ }^{16,24}$ Within each chronic condition cohort, we completed a one-to-one nearest-neighbor match on propensity scores within a caliper restriction. The final cohorts included three matched chronic condition cohorts: diabetes $=608(304$ matched pairs); hypertension = 1244 (622 matched pairs); hyperlipidemia $=564$ (273 matched pairs). See online Appendix for additional detail on propensity score matching.

\section{Outcome Measures}

The biomarker outcomes of interest were hemoglobin A1c $(\mathrm{HbAlc})$ for the diabetes cohort, systolic and diastolic blood pressure (SBP and DBP, respectively) for the hypertension cohort, and LDL for the hyperlipidemia cohort. Threshold values to identify each cohort were based on national consensus guidelines ${ }^{25-28}$ and previous studies. ${ }^{12,29,30}$ Disease was considered "uncontrolled" (regardless of treatment status) for diabetes, hyperlipidemia, and hypertension cohorts, respectively, if $\mathrm{HbA} 1 \mathrm{c} \geq 9 \%, \mathrm{LDL} \geq 160 \mathrm{mg} / \mathrm{ml}$, or at least two elevated blood pressure measurements with either SBP $\geq 150 \mathrm{mmHg}$ or $\mathrm{DBP} \geq 100 \mathrm{mmHg}$. If patients met criteria 
for multiple cohorts, they were included in all cohorts for which they qualified.

To generate hypotheses regarding the nature of observed differences, we also examined prescription orders of diseasespecific medication for each cohort - hypoglycemic drugs for the diabetes cohort, antihypertensive drugs for the hypertension cohort, and antihyperlipidemic drugs for the hyperlipidemia cohort. Appropriate medications were identified within the EHR based on pharmaceutical class, and medication lists were reviewed and agreed upon by two physician researchers.

\section{Analyses}

We examined differences in baseline characteristics between the insured and uninsured patients, tested using standardized differences, chi-square, and $t$ tests. We performed three analyses for each biomarker: (1) time-to-event analysis assessing time from uncontrolled baseline measurement to a follow-up controlled measurement; (2) longitudinal analysis modeling the mean biomarker value over time; and (3) logistic regression analysis to estimate the odds of having a disease-specific medication ordered during the study period.

Time to a controlled follow-up measurement (i.e., event) was defined as the time from baseline elevated measurement to an $\mathrm{HbAlc}$ measurement $<9 \%$ for the diabetes cohort, an LDL measurement $<160 \mathrm{mg} / \mathrm{dL}$ for the hyperlipidemia cohort, and a blood pressure measurement with both $\mathrm{SBP}<$ $150 \mathrm{mmHg}$ and $\mathrm{DBP}<100 \mathrm{mmHg}$ for the hypertension cohort. To examine the relationship between insurance status and time from an elevated to a controlled measurement, KaplanMeier survival curves were plotted, and a Cox proportional hazards model was used to analyze differences in time to controlled measurement by insurance status. Hazard ratios (HRs) were calculated and a robust sandwich variance estimator was used to construct $95 \%$ confidence intervals (CIs) of HRs to account for correlation of subjects within propensity score-matched sets and subjects nested in CHCs. ${ }^{31}$

For the longitudinal analysis, we modeled the mean biomarker over time for insured and uninsured patients. We descriptively produced individual and mean longitudinal profile plots of biomarker measurements by insurance status for each follow-up cohort. Visual examination of the plots showed non-linear patterns of change over time, so we modeled change separately from 0 to 6 months and 6 to 24 months using linear mixed effect models to model the mean biomarkers while accounting for multiple levels of clustering (temporal correlation within individuals, matched pairs, and patients within $\mathrm{CHCs}$ ). Final models were tested for fit, and included independent variables for insurance status, time, "spline" (slope change at 6 months) interactions between time and insurance and the spline and insurance, and covariates with residual imbalance after propensity score matching (see online Appendix). Identical models were used for the sensitivity analyses of the "full population" including those without a follow-up biomarker measurement (see online Appendix).
Adjusted mean values from the final model across three time points $(0,6$, and 24 months) were calculated for both the insured and uninsured groups, and CIs were calculated using a clustered bootstrap procedure (5000 repeats). ${ }^{32}$ Rates of change from baseline to 6 months and from 6 to 24 months were generated, and differences in the rates of mean biomarker change between insured and uninsured groups were tested. Lastly, we assessed between-group differences in whether any disease-specific prescription medications were ordered at any point during the follow-up period, using a generalized estimating equation (GEE) logistic regression model, controlling for covariates with residual imbalance in propensity score models and accounting for clustering of matched patients and patients within clinics.

Analyses were conducted using R version 3.2.1 and SAS version 9.4 software (SAS Institute Inc., Cary, NC). All statistical tests were two-sided, and significance was defined as a $\mathrm{p}$ value $<0.05$. The study was approved by the Oregon Health \& Science University Institutional Review Board.

\section{RESULTS}

Consistent with overall OCHIN health information network demographics, the majority in each chronic disease cohort had household income below the FPL $(>75 \%)$ and resided in urban areas $(>85 \%)$. A large percentage of patients had been previously insured by Medicaid (>80\%) and had more than five visits to an OCHIN clinic prior to the study (>50\%).

Prior to propensity score matching, all chronic disease cohorts showed significant differences between newly insured and uninsured patients across multiple baseline patient and clinic characteristics. After propensity score matching, cohorts showed improvement in the balance of baseline characteristics between insured and uninsured groups, with only two characteristics showing a difference of $>0.1$ standard deviation (SD) between groups (race/ethnicity in the hyperlipidemia cohort/number of pre-baseline encounters for all three cohorts; Table 1). Characteristics showing a difference of $>0.1$ SD were included as categorical covariates in final models.

Kaplan-Meier survival curves and corresponding logrank survival tests showed significantly different survival functions between the insured and uninsured groups in time to achieve a controlled measurement among the diabetes and hypertension cohorts but not the hyperlipidemia cohort (Fig. 1). Among the diabetes and hypertension cohorts, patients who gained Medicaid insurance were significantly more likely to achieve a controlled measurement than those who remained continuously uninsured (diabetes: $[\mathrm{HR}]=$ $1.26, p=0.020$; hypertension: $\mathrm{HR}=1.35, p<0.001$; in the hyperlipidemia cohort, this trend was not statistically significant $[\mathrm{HR}=1.09, p=0.392]$ ).

All biomarkers improved rapidly during the first 6 months after the elevated baseline measurement, then more slowly during months 6 through 24. This trend of changing rates at 
Table 1 Baseline Characteristics of Matched Cohorts

\begin{tabular}{|c|c|c|c|c|c|c|c|c|c|}
\hline & \multicolumn{3}{|c|}{ Diabetes cohort } & \multicolumn{3}{|c|}{ Hypertension cohort } & \multicolumn{3}{|c|}{ Hyperlipidemia cohort } \\
\hline & \multicolumn{3}{|c|}{304 matched pairs } & \multicolumn{3}{|c|}{622 matched pairs } & \multicolumn{3}{|c|}{273 matched pairs } \\
\hline & \multicolumn{3}{|c|}{$N=608$ from $42 \mathrm{CHCs}$} & \multicolumn{3}{|c|}{$N=1244$ from 59 CHCs } & \multicolumn{3}{|c|}{$N=546$ from $44 \mathrm{CHCs}$} \\
\hline & Insured & Uninsured & $\begin{array}{l}\text { Std. } \\
\text { difference }\end{array}$ & Insured & Uninsured & $\begin{array}{l}\text { Std. } \\
\text { difference }\end{array}$ & Insured & Uninsured & $\begin{array}{l}\text { Std. } \\
\text { difference }\end{array}$ \\
\hline \multirow{2}{*}{$\begin{array}{l}\text { Gender, } \% \\
\text { Male } \\
\text { Age at baseline } \\
\text { (years), \% }\end{array}$} & \multirow[b]{2}{*}{52.0} & \multirow[b]{2}{*}{48.0} & -0.079 & \multirow[b]{2}{*}{51.8} & \multirow[b]{2}{*}{51.5} & \multirow[t]{2}{*}{-0.006} & \multirow[b]{2}{*}{42.9} & \multirow[b]{2}{*}{41.4} & \multirow[t]{2}{*}{-0.030} \\
\hline & & & 0.024 & & & & & & \\
\hline $19-39$ & 23.0 & 22.0 & & 18.8 & 19.3 & \multirow[t]{3}{*}{0.013} & 17.2 & 16.1 & \multirow[t]{3}{*}{0.033} \\
\hline $40-49$ & 32.2 & 32.6 & & 33.0 & 33.0 & & 30.8 & 31.9 & \\
\hline \multirow{2}{*}{\multicolumn{3}{|c|}{ Race/ethnicity, \% }} & \multirow{4}{*}{0.092} & 48.2 & 47.8 & & 52.0 & 52.0 & \\
\hline & & & & & & 0.036 & & & $0.130 *$ \\
\hline Hispanic & 26.6 & 30.6 & & 9.7 & 10.3 & & 16.9 & 18.7 & \\
\hline Non-Hispanic & 55.3 & 53.0 & & 72.3 & 72.2 & & 66.7 & 69.2 & \\
\hline white 1 the & & & & & & & & & \\
\hline $\begin{array}{l}\text { Non-Hispanic } \\
\text { other }\end{array}$ & 16.8 & 15.5 & & 15.8 & 15.0 & & 14.3 & 10.3 & \\
\hline $\begin{array}{l}\text { Missing/ } \\
\text { unknown }\end{array}$ & 1.3 & 1.0 & & 2.3 & 2.6 & & 2.2 & 1.8 & \\
\hline Language, \% & & & 0.087 & & & 0.092 & & & 0.059 \\
\hline Spanish & 20.1 & 23.4 & & 5.6 & 5.8 & & 12.5 & 14.3 & \\
\hline English & 74.0 & 71.7 & & 86.7 & 88.8 & & 79.9 & 78.8 & \\
\hline Other & 5.9 & 4.9 & & 6.8 & 4.7 & & 7.0 & 6.2 & \\
\hline Missing/ & 0 & 0 & & 1.0 & 0.8 & & 0.7 & 0.7 & \\
\hline unknown & & & & & & & & & \\
\hline $\begin{array}{l}\text { Federal poverty level } \\
\text { (FPL), \% }\end{array}$ & & & 0.089 & & & 0.037 & & & 0.083 \\
\hline$\leq 100 \%$ FPL & 85.2 & 81.9 & & 84.4 & 83.8 & & 81.0 & 77.7 & \\
\hline$>100 \%$ FPL & 13.2 & 16.1 & & 13.8 & 14.8 & & 18.0 & 21.3 & \\
\hline Missing/ & 1.6 & 2.0 & & 1.8 & 1.5 & & 1.1 & 1.1 & \\
\hline $\begin{array}{l}\text { unknown } \\
\text { Urhan/rural of }\end{array}$ & & & 0054 & & & 0053 & & & 0053 \\
\hline Urban & 93.4 & 92.8 & & 89.9 & 88.3 & & 87.2 & 88.6 & \\
\hline Rural & 5.6 & 6.6 & & 9.7 & 11.3 & & 11.7 & 10.6 & \\
\hline Missing/ & 1.0 & 0.7 & & 0.5 & 0.5 & & 1.1 & 0.7 & \\
\hline $\begin{array}{l}\text { Had prior Medicaid } \\
\text { insurance, } \%\end{array}$ & 86.2 & 84.9 & 0.037 & 86.7 & 86.0 & 0.019 & 85.0 & 82.4 & 0.070 \\
\hline No. of pre-baseline er & ounters, \% & & & & & & & & \\
\hline Mean (SD) & $16.7(23.0)$ & $16.6(18.9)$ & 0.005 & $16.2(20.2)$ & $19.5(25.7)$ & $-0.145^{*}$ & $12.8(21.5)$ & $15.4(17.2)$ & $-0.132 *$ \\
\hline 0 & 7.6 & 6.9 & $0.312 *$ & & & $0.130 *$ & & & $0.294 *$ \\
\hline $1-2$ & 27.6 & 15.8 & & 20.1 & 16.2 & & 26.7 & 21.3 & \\
\hline $3-5$ & 9.2 & 12.5 & & 17.9 & 15.9 & & 20.9 & 15.0 & \\
\hline $6-10$ & 10.2 & 14.5 & & 16.2 & 16.4 & & 15.4 & 14.7 & \\
\hline$>10$ & 45.4 & 50.3 & & 45.8 & 51.5 & & 33.0 & 46.5 & \\
\hline No. of uncontrolled $b$ & marker meas & rements pre-b & $\operatorname{seline}^{\dagger}, \%$ & & & & & & \\
\hline 0 & 75.3 & 73.0 & 0.063 & 24.0 & 22.4 & 0.053 & 92.3 & 91.2 & 0.065 \\
\hline 1 & 11.5 & 13.5 & & 15.1 & 14.2 & & 5.5 & 7.0 & \\
\hline$\geq 2$ & 13.2 & 13.5 & & 60.9 & 63.5 & & 2.2 & 1.8 & \\
\hline $\begin{array}{l}\text { Chronic multi- } \\
\text { morbidity } \%\end{array}$ & 53.6 & 55.6 & -0.040 & 36.2 & 35.1 & 0.024 & 31.1 & 33.0 & -0.039 \\
\hline
\end{tabular}

Bold $=$ significant at $p<0.05$. *Standardized difference $>0.1$

${ }^{\prime}$ For diabetes cohort: HbAlc $\geq 9.0 \%$; for hypertension cohort: systolic blood pressure (SBP) $\geq 160 \mathrm{mmHg}$ and/or diastolic blood pressure (DBP) $\geq 100 \mathrm{mmHg}$; for hyperlipidemia cohort: low-density lipoprotein $(\mathrm{LDL}) \geq 160 \mathrm{mg} / \mathrm{dL}$

${ }^{\mp}$ Chronic conditions assessed: hypertension, hyperlipidemia, diabetes, coronary artery disease, and chronic obstructive pulmonary disease/asthma, $\geq 2$ of the 5 chronic conditions present at baseline

6 months was accounted for in our longitudinal models of biomarkers. For all three chronic disease cohorts, the average biomarker measurements, as represented by locally weighted scatterplot smoothing (LOWESS) curves, were consistently (and increasingly) lower for the group that gained Medicaid insurance compared to the continuously uninsured, though statistical differences in rates of improvement were observed only during the first 6 months among the diabetes cohort ($0.34 \% /$ month compared to $-0.26 \% /$ month, $p=0.02$; Fig. 2 , Table 2).
A large percentage of the total patients were likely to receive an order for prescription medication for their uncontrolled chronic condition during the study period $(>99 \%$ in diabetes cohort, $>85 \%$ in hypertension cohort, and $>75 \%$ in hyperlipidemia cohort). Among all three cohorts, a slightly larger proportion of patients who gained Medicaid received a prescription for medication compared to those who remained uninsured; however, this difference was significant only for the hyperlipidemia cohort $(85.4 \%$ vs. $78.4 \%, p<0.01$; Table 3). 

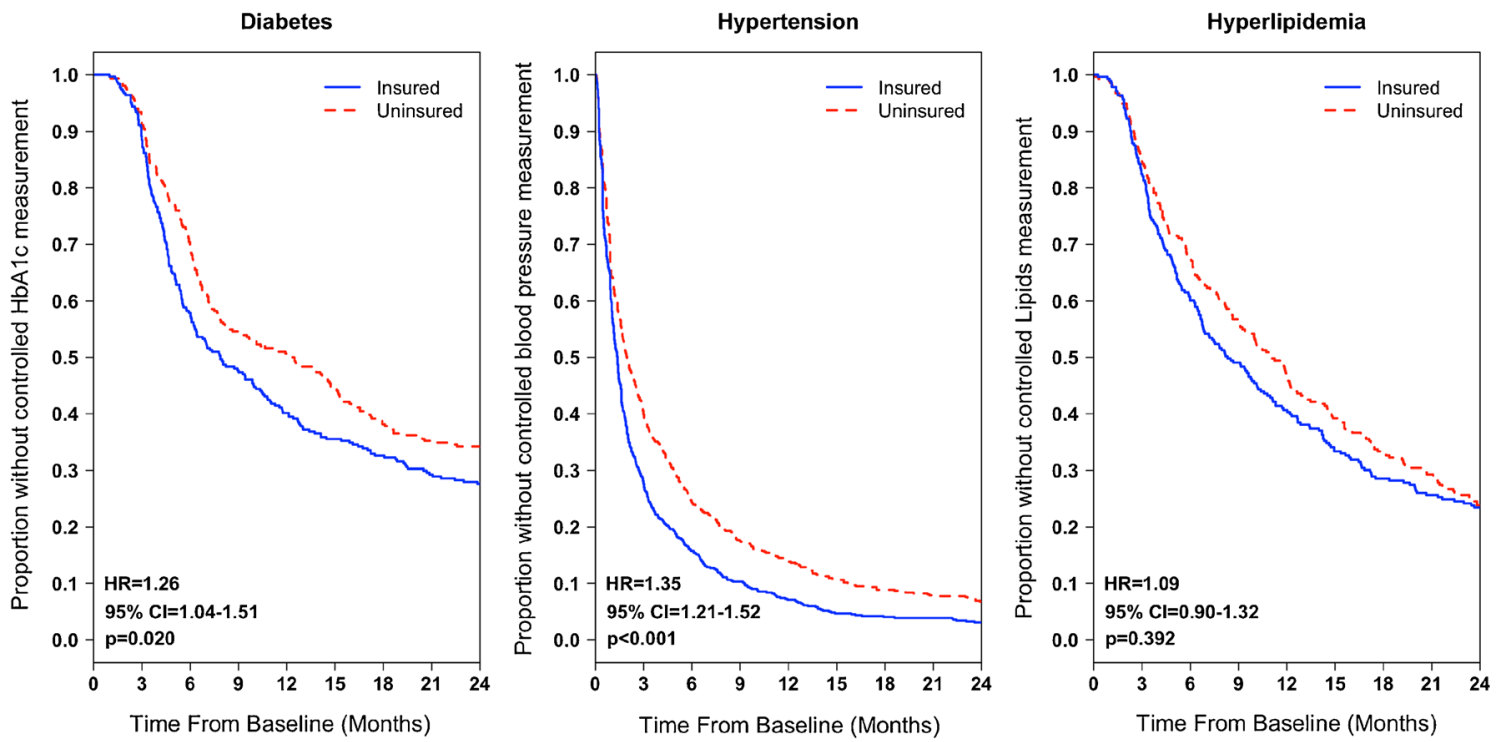

Figure 1 Kaplan-Meier survival curves: time from baseline elevated measurement to a controlled measurement by insurance category among propensity score-matched patients. $H R$ hazard ratio, $C I$ confidence interval. Note: Cox regression modeling was used to estimate HRs, with $p$ values noted on each figure. Models were adjusted for covariates with residual imbalance (SD $\geq 0.10)$. A robust sandwich variance estimator was used to account for correlation of subjects within propensity score-matched sets and subjects nested in community health centers.

\section{DISCUSSION}

This study produced three principal findings among $\mathrm{CHC}$ patients with an uncontrolled chronic condition: (1) both insured and uninsured patients experienced improvement in biomarkers over time; (2) in two of the three cohorts, patients who gained Medicaid coverage were more likely to achieve control within the study period; and (3) most patients received prescriptions for disease-specific medications regardless of insurance status.

These findings are consistent with a large body of literature demonstrating the importance of both health insurance and a consistent usual source of care in achieving better health. ${ }^{4,33-}$ ${ }^{38}$ They also support previous studies demonstrating the excellent quality of care provided by $\mathrm{CHCs} .{ }^{3,6-8}$ These findings surpass those of prior studies, as they reflect an objective quantification of longitudinal health outcomes and the inclusion of an uninsured comparison group.

Our findings demonstrate the impact of new access to Medicaid on the health of CHC patients. Gaining coverage was associated with improved biomarkers for this group of patients already benefiting from a consistent usual source of care, suggesting that expansions in Medicaid coverage will likely be associated with improvements in the health of other uninsured populations. Future analyses could assess the long-term clinical and economic impacts of this health improvement.

Surprisingly, though patients in the diabetes and hypertension cohorts who gained Medicaid were more likely to achieve a controlled biomarker measurement than those who were uninsured, we did not identify significant differences in prescription rates for disease-specific medications. Patients in the hyperlipidemia cohort who gained Medicaid insurance were no more likely to achieve a controlled measurement than uninsured patients, but they were more likely to have a prescription ordered for lipid-lowering medication. This result is likely attributable to the lower rate of follow-up for this cohort, as these differences were not observed in a sensitivity analysis of the full population (see online Appendix). The comparable rates of prescribing suggest that clinicians' prescribing patterns are similar regardless of insurance status. It is possible that uninsured patients filled prescriptions less frequently or experienced delays due to an inability to afford medications; pharmacy data on dispensed prescriptions were not available to confirm this theory. It is also possible that between-group differences in unmeasured medical or social factors (e.g., health literacy, patient engagement) played a role in biomarker improvement. Though these factors were not measurable with our data, future studies could expand population descriptors to explore the additional complex social and clinical factors that may affect care.

This study provokes many questions in the context of the ACA. With early studies showing increased utilization of healthcare at $\mathrm{CHCs},{ }^{39-41}$ maintaining access with growing patient panels will be essential to providing timely care to patients with chronic diseases. ${ }^{42}$ This may have both workforce and workflow implications, and may call for innovations to our healthcare delivery system.

\section{Limitations}

The clinical impact of small absolute differences in biomarker changes is uncertain, though there may be population impacts of a more broadly insured patient population at CHCs not captured in this study. ${ }^{43}$ For example, a greater number of insured patient visits may facilitate additional resources for and implementation of other activities such as behavioral health counseling or more ambitious clinic-wide quality improvement efforts that may improve patients' health outcomes. Therefore, it is possible that unmeasured services provided to all patients contributed to the observed improvements in biomarkers in both the insured and uninsured groups. Our main analytic method was analogous to a 

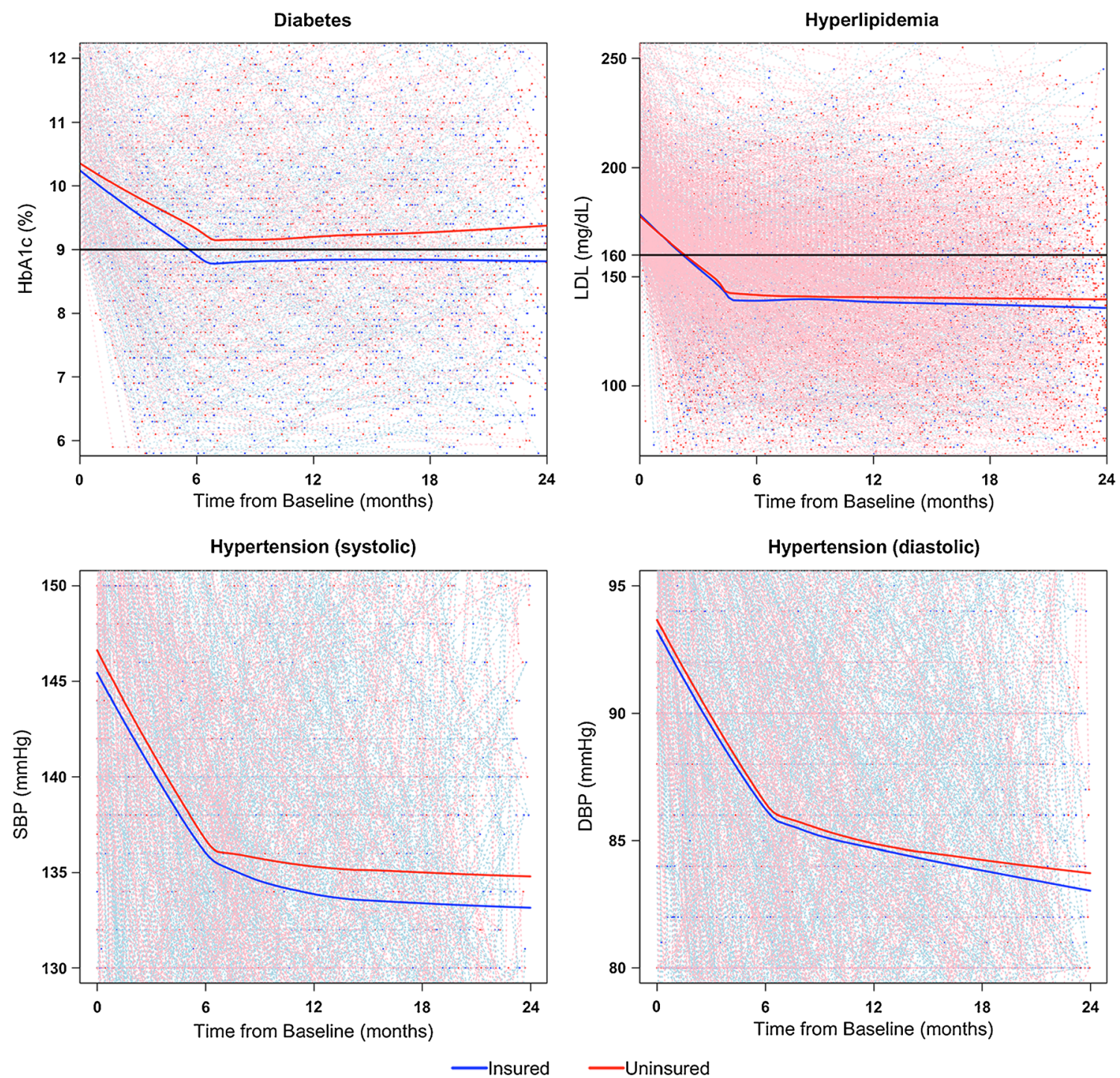

Figure 2 Patient-specific profile plots and average LOWESS curves: biomarkers over time by insurance category among propensity scorematched patients. Note: Black lines denote limits of "controlled" range. LOWESS curves are denoted by solid lines, and represent a locally weighted average of biomarkers over time, stratified by insurance status. Thin dashed lines represent patient-specific profile plots. Due to large sample sizes, the points in the two hypertension cohort graphs represent 100 matched pairs selected at random, whereas the LOWESS curves reflect results from the entire hypertension cohort.

per-protocol approach used in randomized controlled trials, where we analyzed data from subjects who did not deviate from the protocol (i.e,. gained Medicaid or were continuously uninsured). This approach could have introduced bias. Future studies could apply an intent-to-treat approach with a broader comparison group of patients who were uninsured and/or gained some insurance in the follow-up period. Propensity score methods allowed us to control for an extensive list of baseline covariates, including FPL and comorbidities that influence Medicaid eligibility, but unmeasured confounding may still exist. One likely scenario is self-selection into Medicaid among certain individuals with unmeasured health events occurring between baseline and followup; if patients with worse health status self-selected into Medicaid, this would create a bias toward the null with regard to the outcomes investigated here.

Although the direct health metrics available through the EHR represent a novel means of capturing improvements in health outcomes (arguably, a new gold standard), using the EHR in this study limited our perspective to patients who visited a CHC. Thus, we cannot report on the health of those who did not (or could not) access CHC care. Since lack of insurance is a known barrier to accessing healthcare, ${ }^{11,44}$ the uninsured comparison group in this study is not representative of all uninsured patients. Though it is possible patients received additional care outside our network, prior studies suggest that patients continue to utilize $\mathrm{CHC}$ care after gaining health insurance rather than transitioning care elsewhere. ${ }^{40,45-49}$ Our findings are not generalizable to other health outcomes, other chronic diseases, or other health systems. Due to the relatively recent implementation of EHRs from which to capture data, we were unable to assess the impact of Medicaid on long-term health outcomes such as mortality. Additionally, given the study period (20082011), we were unable to produce pre-period biomarker trends to judge whether they looked similar between insurance groups. 
Table 2 Mean Biomarker Levels and Difference in Mean Biomarker Rates at Baseline, 6 Months, and 24 Months by Insurance Status

\begin{tabular}{|c|c|c|c|c|c|c|c|}
\hline \multirow[t]{2}{*}{$\overline{\text { Outcome }}$} & \multicolumn{3}{|c|}{ Mean biomarker levels and 95\% CI } & \multicolumn{4}{|c|}{ Rates of change (units/month) } \\
\hline & Baseline & 6 months & 24 months & 0 to 6 months & $p$ value & 6 to 24 months & $p$ value \\
\hline \multicolumn{8}{|c|}{$\operatorname{HbA1c}(\%)(n=608)$} \\
\hline Insured & $10.6(10.4,10.7)$ & $9.0(8.8,9.3)$ & $9.4(9.2,9.7)$ & -0.34 & \multirow[t]{2}{*}{0.021} & 0.03 & \multirow[t]{2}{*}{0.304} \\
\hline Uninsured & $10.6(10.5,10.7)$ & $9.1(8.8,9.3)$ & $9.4(9.3,9.7)$ & -0.26 & & 0.02 & \\
\hline \multicolumn{8}{|c|}{$\operatorname{SBP}(\mathrm{mmHg})(n=1244)$} \\
\hline Insured & $147.8(146.9,149.0)$ & $134.8(133.6,135.7)$ & $135.4(134.3,136.9)$ & -2.18 & \multirow[t]{2}{*}{0.377} & 0.04 & \multirow[t]{2}{*}{0.965} \\
\hline Uninsured & $149.1(148.0,150.3)$ & $136.8(135.7,138.0)$ & $137.5(136.2,139.0)$ & -2.04 & & 0.03 & \\
\hline \multicolumn{8}{|c|}{$\mathrm{DBP}(\mathrm{mmHg})(n=1244)$} \\
\hline Insured & $94.1(93.6,94.9)$ & $84.6(84.1,85.5)$ & $84.4(83.4,85.5)$ & -1.57 & \multirow[t]{2}{*}{0.248} & -0.01 & \multirow[t]{2}{*}{0.329} \\
\hline Uninsured & $94.7(94.1,95.5)$ & $86.0(85.4,86.9)$ & $85.1(84.1,86.1)$ & -1.45 & & -0.05 & \\
\hline \multicolumn{8}{|c|}{$\mathrm{LDL}(\mathrm{mg} / \mathrm{dL})(n=546)$} \\
\hline Insured & $181.3(180.4,185.2)$ & $131.0(122.3,134.9)$ & $148.5(142.3,158.5)$ & -8.37 & \multirow[t]{2}{*}{0.445} & 0.97 & \multirow[t]{2}{*}{0.150} \\
\hline Uninsured & $181.5(179.0,185.2)$ & $135.5(125.3,137.8)$ & $141.3(138.7,152.7)$ & -7.78 & & 0.32 & \\
\hline
\end{tabular}

Bold $=$ significant at $p<0.05$

Likelihood ratio tests for spline were significant for all models at $p<0.001$

CIs constructed using 5000 clustered bootstrap replicates

Hyperlipidemia cohort model adjusted for: racelethnicity, number of encounters prior to baseline

Hypertension cohort model adjusted for: number of encounters prior to baseline

SBP systolic blood pressure, DBP diastolic blood pressure, LDL low-density lipoprotein, CI confidence interval

Future research should consider evaluating the parallel trends assumption in biomarker levels when assessing the impact of gaining Medicaid coverage on health outcomes.

Assessment of continuity of insurance status was beyond the scope of this study. It is possible that some individuals who were classified as "gained new Medicaid" actually lost coverage after their first coverage window of 6 months. Churning on and off Medicaid coverage is common among CHC patients $^{50}$ and has been associated with poor health outcomes. ${ }^{4,51-53}$ Any heterogeneity in insurance status could have diluted an underlying effect.

As with any natural policy experiment, the results of this study reflect observational study design enabling timely, "realworld" analysis; this study design is subject to unmeasured confounding and bias. Results may not generalize to other populations or Medicaid expansions. While this study provides insight into the outcome of a pre-ACA Oregon Medicaid expansion, it cannot predict more widespread outcomes in the setting of the ACA. More research is urgently needed to examine the impacts of these new policies.

Table 3 Proportion of Patients with Disease-Specific Medication Ordered During the Study Period

\begin{tabular}{llll}
\hline Cohort & $\begin{array}{l}\text { Proportion } \\
\text { with medication } \\
\text { prescribed }\end{array}$ & OR 95\% CI & $p$ value* \\
\hline Diabetes & & $1.51(0.25,9.14)$ & 0.657 \\
$\quad$ Insured & $99.3 \%$ & $1.41(0.97,2.06)$ & \\
$\quad \begin{array}{l}\text { Uninsured } \\
\text { Hypertension } \\
\text { Insured }\end{array}$ & $99.1 \%$ & & \\
$\quad$ Uninsured & $90.8 \%$ & $1.68(1.10,2.58)$ & 0.016 \\
$\begin{array}{c}\text { Hyperlipidemia } \\
\quad \text { Insured }\end{array}$ & $85.4 \%$ & & \\
$\quad$ Uninsured & $78.4 \%$ & & \\
\hline
\end{tabular}

OR odds ratio, CI confidence interval

* $p$ values based on generalized estimating equation logistic regression model with clustering effect of propensity score-matched pair and patients within CHCs, adjusted for covariates with residual imbalance

\section{CONCLUSIONS}

New enrollment in Medicaid during a period of Medicaid expansion in Oregon was associated with improved health outcomes among cohorts of CHC patients with uncontrolled diabetes and hypertension. These findings argue for Medicaid expansion and continued support for CHCs, and continued assessment of the complex relationships between insurance, access to a usual source of care, and health outcomes. The EHR provides a novel lens through which to examine health policies, particularly those impacting vulnerable populations.

Corresponding Author: Heather Angier, MPH; Oregon Health \& Science University, Portland, OR, USA (e-mail: angierh@ohsu.edu).

\section{Compliance with Ethical Standards:}

Funding: This project was funded in part by the National Institutes of Health/National Heart, Lung, and Blood Institute, RO1HL107647, and the Agency for Healthcare Research and Quality, RO1HSO2427O.

Prior Presentations: These results were presented at the 43rd North American Primary Care Research Group Annual Meeting, October 2428, 2015, in Cancun, Mexico.

Conflict of Interest: The authors declare that they do not have a conflict of interest.

\section{REFERENCES}

1. Henry J. Kaiser Family Foundation. Key Facts about the Uninsured Population 2016. http://kff.org/uninsured/fact-sheet/key-facts-aboutthe-uninsured-population/. Accessed March, 2017.

2. Shin P, Sharac J, Rosenbaum S, Paradise J. Community Health Centers: a 2013 profile and prospects as ACA implementation proceeds. 2015.

3. Hicks LS, O'Malley AJ, Lieu TA, et al. The quality of chronic disease care in U.S. community health centers. Health Aff. 2006;25(6):17121723.

4. Gold R, DeVoe JE, McIntire PJ, Puro JE, Chauvie SL, Shah AR. Receipt of diabetes preventive care among safety net patients associated with differing levels of insurance coverage. J Am Board Fam Med. 2012;25(1):42-49.

5. Henry J. Kaiser Family Foundation. Distribution of revenue by source for federally-funded federally qualified health centers. 2015; http://kff.org/ 
other/state-indicator/distribution-of-revenue-by-source-for-federallyfunded-federally-qualified-health-centers. Accessed March, 2017.

6. Gurewich D, Tyo KR, Zhu J, Shepard DS. Comparative performance of community health centers and other usual sources of primary care. J Ambul Care Manage. 2011;34(4):380-390.

7. Goldman LE, Chu PW, Tran H, Romano MJ, Stafford RS. Federally qualified health centers and private practice performance on ambulatory care measures. Am J Prev Med. 2012;43(2):142-149.

8. Bruen BK, Ku L, Lu X, Shin P. No evidence that primary care physicians offer less care to Medicaid, community health center, or uninsured patients. Health Aff. 2013;32(9): 1624-1630.

9. Starfield B, Shi L. The medical home, access to care, and insurance: a review of evidence. Pediatrics. 2004;113(5 supplement):1493-1498.

10. McWilliams JM, Meara E, Zaslavsky AM, Ayanian JZ. Health of previously uninsured adults after acquiring Medicare coverage. JAMA. 2007;298(24):2886-2894

11. Freeman JD, Kadiyala S, Bell JF, Martin DP. The causal effect of health insurance on utilization and outcomes in adults: a systematic review of US studies. Med Care. 2008;46(10):1023-1032.

12. Zhang JX, Huang ES, Drum ML, et al. Insurance status and quality of diabetes care in community health centers. Am J Public Health. 2009;99(4):742-747.

13. Finkelstein A, Taubman $\mathbf{S}$, Wright $\mathbf{B}$, et al. The Oregon health insurance experiment: evidence from the first year. $\mathrm{Q} \mathrm{J}$ Econ. 2012;127(3): 1057-1106.

14. Baicker K, Taubman SL, Allen HL, et al. The Oregon experiment-effects of Medicaid on clinical outcomes. N Engl J Med. 2013;368(18): 17131722.

15. Cowburn S, Carlson MJ, Lapidus JA, DeVoe JE. The association between insurance status and cervical cancer screening in community health centers: exploring the potential of electronic health records for population-level surveillance, 2008-2010. Prev Chronic Dis. 2013;10, E173.

16. Marino M, Bailey SR, Gold R, et al. Receipt of preventive services after Oregon's randomized Medicaid experiment. Am J Prev Med. 2015.

17. Writing Group M, Mozaffarian D, Benjamin EJ, et al. Heart disease and stroke statistics-2016 update: a report from the American Heart Association. Circulation. 2016;133(4):e38-e360.

18. Pham HH, Schrag D, Hargraves JL, Bach PB. Delivery of preventive services to older adults by primary care physicians. JAMA. 2005;294(4):473-481.

19. Bryant LL, Chin NP, Cottrell LA, et al. Perceptions of cardiovascular health in underserved communities. Prev Chronic Dis. 2010;7(2):A30.

20. Ferdinand KC, Armani AM. Cardiovascular disease in racial and ethnic minorities. New York: Humana Press; 2009.

21. Graham G. Disparities in cardiovascular disease risk in the United States. Curr Cardiol Rev. 2015;11(3):238-245.

22. DeVoe JE, Gold $\mathbf{R}$, Spofford $\mathbf{M}$, et al. Developing a network of community health centers with a common electronic health record: description of the Safety Net West Practice-based Research Network (SNW-PBRN). J Am Board Fam Med. 2011;24(5):597-604.

23. Andersen R, Aday LA. Access to medical care in the U.S.: realized and potential. Med Care. 1978;16(7):533-546.

24. Bailey SR, Hoopes M, Marino M, et al. Effect of gaining insurance coverage on smoking cessation in community health centers: a cohort study. J Gen Intern Med. 2016; Jun 21 [Epub ahead of print]

25. American Diabetes Association. Standards of medical care in diabetes-2014. Diabetes Care. 2014;37(Suppl 1):S14-S80.

26. National Cholesterol Education Program Expert Panel. Report of the National Cholesterol Education Program (NCEP) Expert Panel on Detection, Evaluation, and Treatment of High Blood Cholesterol in Adults (Adult Treatment Panel III) final report. Circulation. 2002;106(25):31433421.

27. James PA, Oparil S, Carter BL, et al. 2014 evidence-based guideline for the management of high blood pressure in adults: report from the panel members appointed to the Eighth Joint National Committee (JNC 8). JAMA. 2014;311(5):507-520.

28. Chobanian AV, Bakris GL, Black HR, et al. Seventh Report ofthe Joint National Committee on Prevention,Detection, Evaluation, and Treatment of HighBlood Pressure. Hypertension. 2003;42(6):1206-1252.

29. Jackson GL, Edelman D, Weinberger M. Simultaneous control of intermediate diabetes outcomes among Veterans Affairs primary care patients. J Gen Intern Med. 2006;21(10):1050-1056.

30. Flegal KM, Kit BK, Orpana H, Graubard BI. Association of all-cause mortality with overweight and obesity using standard body mass index categories: a systematic review and meta-analysis. JAMA. 2013;309(1):71-82.

31. Cameron AC, Miller DL. A practitioner' s guide to cluster- robust inference. J Hum Resour. 2015;50(2):317-372.

32. Mooney CZ, Duval RD, Duval R. Bootstrapping: a nonparametric approach to statistical inference. Sage; 1993.

33. DeVoe JE, Fryer GE, Phillips R, Green L. Receipt of preventive care among adults: insurance status and usual source of care. Am J Public Health. 2003;93(5):786-791

34. Goldstein RB, Rotheram-Borus MJ, Johnson MO, et al. Insurance coverage, usual source of care, and receipt of clinically indicated care for comorbid conditions among adults living with human immunodeficiency virus. Med Care. 2005;43(4):401-410.

35. Solotaroff R, Wright B, Carlson M, Edlund T, Smith J. Insurance instability and usual source of care among chronically ill Medicaid patients. J Gen Intern Med. 2006;21(Suppl. 4):74.

36. DeVoe JE, Tillotson CJ, Wallace LS. Usual source of care as a health insurance substitute for U.S. adults with diabetes? Diabetes Care. 2009;32(6):983-989.

37. DeVoe JE, Tillotson CJ, Lesko SE, Wallace LS, Angier H. The case for synergy between a usual source of care and health insurance coverage. J Gen Intern Med. 2011:26(9):1059-1066.

38. DeVoe JE, Tillotson CJ, Wallace LS, Lesko SE, Pandhi N. Is health insurance enough? A usual source of care may be more important to ensure a child receives preventive health counseling. Matern Child Health J. 2012;16(2):306-315.

39. Sommers BD, Buchmueller T, Decker SL, Carey C, Kronick R. The Affordable Care Act has led to significant gains in health insurance and access to care for young adults. Health Aff. 2013;32(1):165-174.

40. Angier H, Hoopes M, Gold R, et al. An early look at rates of uninsured safety net clinic visits after the Affordable Care Act. Ann Fam Med. 2015;13(1): 10-16.

41. Hoopes MJ, Angier H, Gold R, et al. Utilization of Community Health Centers in Medicaid Expansion and Nonexpansion States, 2013-2014. J Ambul Care Manage. 2016.

42. Tai-Seale M, Wilson CJ, Panattoni L, et al. Leveraging electronic health records to develop measurements for processes of care. Health Serv Res. 2014;49(2):628-644

43. Pagan JA, Carlson EK. Assessing long-term health and cost outcomes of patient-centered medical homes serving adults with poor diabetes control. J Prim Care Commun Health. 2013;4(4):281-285.

44. Buchmueller TC, Grumbach K, Kronick R, Kahn JG. The effect of health insurance on medical care utilization and implications for insurance expansion: a review of the literature. Med Care Res Rev. 2005;62(1):3-30

45. Hatch B, Bailey SR, Cowburn S, Marino M, Angier H, DeVoe JE. Community health center utilization following the 2008 Medicaid expansion in Oregon: implications for the Affordable Care Act. Am J Public Health. 2016; 106(4):645-650.

46. DeVoe JE, Marino M, Gold R, et al. Community health center use after Oregon's randomized Medicaid experiment. Ann Fam Med. 2015;13(4):312-320.

47. Gold R, Bailey SR, O'Malley JP, et al. Estimating demand for care after a Medicaid expansion: lessons from Oregon. J Ambul Care Manage. 2014;37(4):282-292

48. O'Malley JP, O'Keeffe-Rosetti M, Lowe RA, et al. Health care utilization rates after Oregon's 2008 Medicaid expansion: within-group and between-group differences over time among new, returning, and continuously insured enrollees. Med Care. 2016;54(11):984-991.

49. Heintzman J, Bailey SR, Hoopes MJ, et al. Agreement of Medicaid claims and electronic health records for assessing preventive care quality among adults. J Am Med Inform Assoc. 2014;21(4):720-724.

50. Hatch B, Tillotson C, Angier H, et al. Using the electronic health record for assessment of health insurance in community health centers. J Am Med Inform Assoc. 2016;23(5):984-990.

51. Cowburn S, Carlson M, Lapidus J, Heintzman J, Bailey S, DeVoe JE. Insurance continuity and human papillomavirus vaccine uptake in Oregon and California Federally Qualified Health Centers. Am J Public Health. 2014; 104(9):e71-e79.

52. Gold R, DeVoe JE, Shah A, Chauvie S. Insurance continuity and receipt of diabetes preventive care in a network of Federally Qualified Health Centers. Med Care. 2009;47(4):431-439.

53. DeVoe JE, Graham A, Krois L, Smith J, Fairbrother GL. "Mind the Gap" in children's health insurance coverage: does the length of a child's coverage gap matter? Ambul Pediatr. 2008;8(2):129-134 